\title{
KARAKTERISASI SENSOR PHOTODIODA, DS18B20, DAN KONDUKTIVITAS PADA RANCANG BANGUN SISTEM DETEKSI KEKERUHAN DAN JUMLAH ZAT PADAT TERLARUT DALAM AIR
}

\author{
Zulfiah Ayu Kurnia Sari ${ }^{1, a)}$, Handjoko Permana ${ }^{\text {b) }}$, Widyaningrum Indrasaric ${ }^{\text {c) }}$ \\ ${ }^{1)}$ Program Studi Fisika, FMIPA, Universitas Negeri Jakarta, Jl. Rawamangun Muka, Jakarta Timur 13220

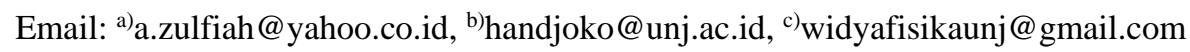

\begin{abstract}
Abstrak
Air minum yang layak untuk dikonsumsi adalah air minum yang memiliki parameter tidak berbau, tidak berasa, jernih, suhu sebaiknya dibawah suhu udara, dan jumlah zat padat terlarut (TDS) yang rendah. Pada sistem deteksi kekeruhan dan jumlah zat padat terlarut dalam air ini diperlukan beberapa perangkat sensor. Keakuratan sensor merupakan suatu hal yang penting untuk menunjang efektivitas sistem. Pada penelitian ini dilakukan karakterisasi sensor ds18b20 sebagai pendeteksi suhu, sensor photodioda sebagai pendeteksi kekeruhan, dan sensor konduktivitas sebagai pendeteksi jumlah zat padat terlarut $(T D S)$ dalam air serta menggunakan arduino sebagai mikrokontrolernya. Karakterisasi dilakukan dengan membandingkan keluaran sensor dengan alat uji laboratorium. Hasil karakterisasi menunjukkan bahwa masing-masing sensor pengukuran memiliki variasi error yaitu sensor photodioda dengan kesalahan relatif sebesar $3.13 \%$, sensor ds $18 \mathrm{~b} 201.77 \%$, dan sensor konduktivitas $2.42 \%$.
\end{abstract}

Kata-kata kunci: suhu, kekeruhan, TDS, arduino.

\begin{abstract}
Drinking water worth consumption are those that should be odorless, tasteless, clean, the temperatures preferably below air temperature, and low amounts of dissolved solids. On this turbidity and total dissolved solid water system is required some sensor devices. The accuracy of the sensor is an important thing to support the effectiveness of the system. In this research, the calibration of ds $18 \mathrm{~b} 20$ sensor as temperature detector, photodiode sensor as turbidity detector, and conductivity sensor as a detector of dissolved solid (TDS) in water and using Arduino as a microcontroller. The characterization is done by comparing the sensor output with laboratory test equipment. The result of characterization means that each measurement sensor has a variation error that is photodiode sensor with relative error $3.13 \%$, sensor ds $18 \mathrm{~b} 201.77 \%$, and conductivity sensor $2.42 \%$.
\end{abstract}

Keywords: temperature, turbidity, TDS, Arduino. 


\section{PENDAHULUAN}

Menurut Departemen Kesehatan Indonesia, air minum yang layak untuk dikonsumsi adalah air minum yang memiliki parameter tidak berbau, tidak berasa, tidak berwarna, tidak keruh atau jernih, dan dengan suhu sebaiknya dibawah suhu udara sedemikian rupa sehingga menimbulkan rasa nyaman, dan jumlah zat padat terlarut (TDS) yang rendah [1]. Dewasa ini sudah ada instrumentasi yang digunakan untuk pengujian kualitas pada air, salah satunya yaitu turbidimeter. Turbidimeter adalah alat pengujian air yang berfungsi untuk mengukur tingkat kekeruhan air. Air yang keruh akan menyebabkan cahaya yang melewatinya akan mengalami pengurangan intensitas cahaya yang signifikan. Hal tersebut dikarenakan cahaya yang melewati air keruh mengalami penyerapan (absorbsi), pemantulan (refleksi), pembiasan (refraksi), dan diteruskan (transmisi) [2].

Saat ini alat uji kualitas air hanya dimiliki olek pihak tertentu, sehingga menyebabkan kurang efisien untuk mengetahui kualitas air yang baik atau tidak. Oleh karena itu perlu dikembangkan sistem deteksi kekeruhan dan jumlah zat padat terlarut dalam air yang portable.

Sistem ini didesain untuk mendeteksi parameter kekeruhan, jumlah zat padat terlarut (TDS) dalam air yang dilengkapi oleh sensor suhu. Pada sistem ini digunakan sensor photodioda dan LED biru sebagai pendeteksi kekeruhan, ds18b20 sebagai pendeteksi suhu, dan sensor konduktivitas sebagai pendeteksi jumlah zat padat terlarut (TDS). Untuk mengetahui tingkat akurasi dari masing-masing sensor yang digunakan, maka dilakukan karakterisasi dengan membandingkan nilai keluaran sensor dengan alat uji yang sudah ada pada laboratorium, yang nantinya akan dijadikan acuan dalam pembuatan sistem ini.

\section{METODE PENELITIAN}

Metode Penelitian yang digunakan yaitu eksperimen dengan mengembangkan deteksi kualitas air berdasarkan sifat kekeruhan dan jumlah zat padat terlarut yang berbasis arduino uno dan nantinya akan terintegrasi dengan android.

Pada pengukuran kekeruhan digunakan photodioda sebagai receiver dan LED biru sebagai transmitter. Prinsip kerjanya yaitu dengan cara melewatkan larutan diantara receiver dan transmitter. Sedangkan untuk pengukuran suhu menggunakan sensor suhu ds18b20. Sensor digital ini memiliki rentang pengukuran suhu $-55^{\circ} \mathrm{C}-150^{\circ} \mathrm{C}[3]$.

Untuk pengukuran jumlah zat padat terlarut menggunakan sensor konduktivitas. Karakterisasi sensor ds18b20 dan konduktivitas yaitu dengan cara memasukan bagian sensor tersebut kedalam larutan agar dapat dilihat seberapa besar nilai keluarannya.

TABEL 1. Daftar sampel larutan uji

\begin{tabular}{cc}
\hline No Sampel & Bahan \\
\hline 1 & Air PAM \\
2 & Kopi 1/2sdk kecil \\
3 & Kopi 3/4sdk kecil \\
4 & Kopi 1sdk kecil \\
5 & Kopi 5/4sdk kecil \\
\hline
\end{tabular}

Pengambilan data dilakukan dengan menggunakan beberapa sampel larutan. Untuk parameter kekeruhan dan jumlah zat padat terlarut digunakan 5 sampel larutan yang berbeda (Tabel 1). Sedangkan untuk parameter suhu, digunakan satu sumber air yang sama dengan tingkat suhu yang berbeda.

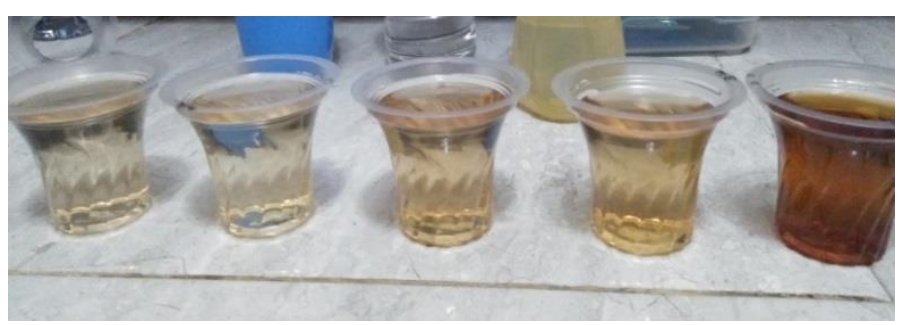

GAMBAR 1. Sampel larutan 


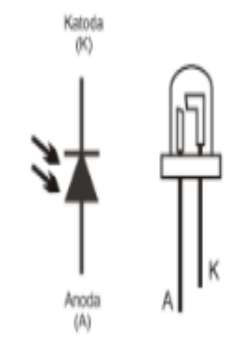

a)

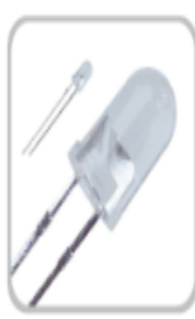

GAMBAR 2. a)Sensor photodioda, b)Sensor konduktivitas, dan c)Sensor ds 18 b20

Sensor yang digunakan pada saat kalibrasi sebanyak tiga buah yaitu, sensor photodioda, ds18b20, dan sensor konduktivitas. Sensor- sensor tersebut nantinya akan diletakan dalam satu kotak yang sudah terintegrasi dengan mikrokontroler. Besar kesalahan relatif sensor dihitung dengan menggunakan persamaan berikut.

$$
\operatorname{Error}(\%)=\frac{|P S-P L|}{P L} \times 100 \%
$$

Dengan PS adalah pembacaan nilai pada sensor yang digunakan, dan PL adalah pembacaan nilai sebenarnya atau yang telah diuji menggunakan alat laboratorium.

\section{HASIL DAN PEMBAHASAN}

\section{a. Sensor Suhu ds18b20}

Pada karakterisasi sensor suhu ds18b20 dilakukan dengan membandingkan nilai keluaran sensor (nilai digital) dengan nilai pada termometer air raksa. Baik keluaran pada sensor maupun pada termometer memiliki satuan celcius $\left({ }^{\circ} \mathrm{C}\right)$. Hasil pengukuran dirangkum pada tabel 2. Kesalahan relatif pengukuran dihitung menggunakan persamaan (1) sehingga diperoleh grafik pada gambar 3. Dari grafik tersebut dapat dilihat bahwa kesalahan relatif pengukuran maksimum yaitu sebesar $3.53 \%$.

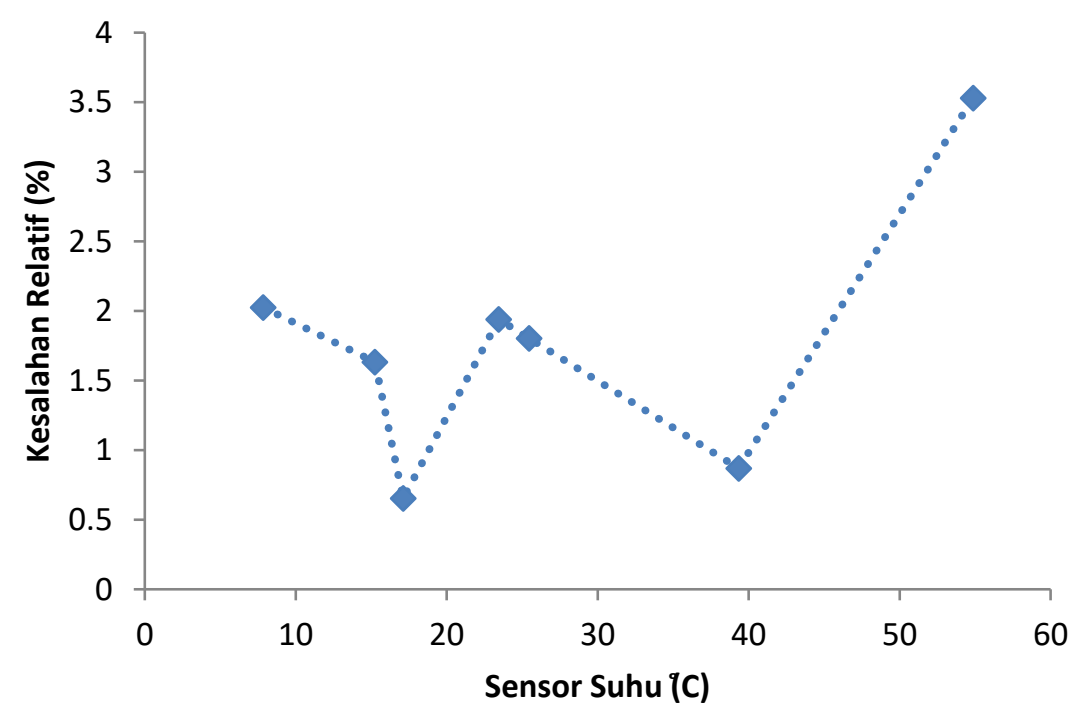

GAMBAR 3. Grafik hubungan nilai kesalahan relatif terhadap keluaran sensor suhu 
TABEL 2. Data nilai sensor suhu dan termometer

\begin{tabular}{ccc}
\hline $\begin{array}{c}\text { Sensor } \\
\text { Suhu }\left({ }^{\circ} \mathrm{C}\right)\end{array}$ & $\begin{array}{c}\text { Termometer } \\
\left({ }^{\circ} \mathrm{C}\right)\end{array}$ & $\begin{array}{c}\text { Kesalahan Relatif }(\%) \\
7,84\end{array}$ \\
\hline 15,24 & 15 & 2,02 \\
17,11 & 17 & 1,63 \\
23,45 & 23 & 0,65 \\
25,45 & 25 & 1,94 \\
39,34 & 39 & 1,8 \\
54,87 & 53 & 0,87 \\
\hline
\end{tabular}

\section{b. Sensor Photodioda}

Pada karakterisasi sensor photodioda dilakukan dengan membandingkan hasil tegangan keluaran pada sensor dengan pengukuran sampel kekeruhan pada laboratorium. Hasil pengukuran dirangkum pada tabel 3. Kesalahan relatif pengukuran dihitung menggunakan persamaan (1) sehingga diperoleh grafik pada gambar 4.

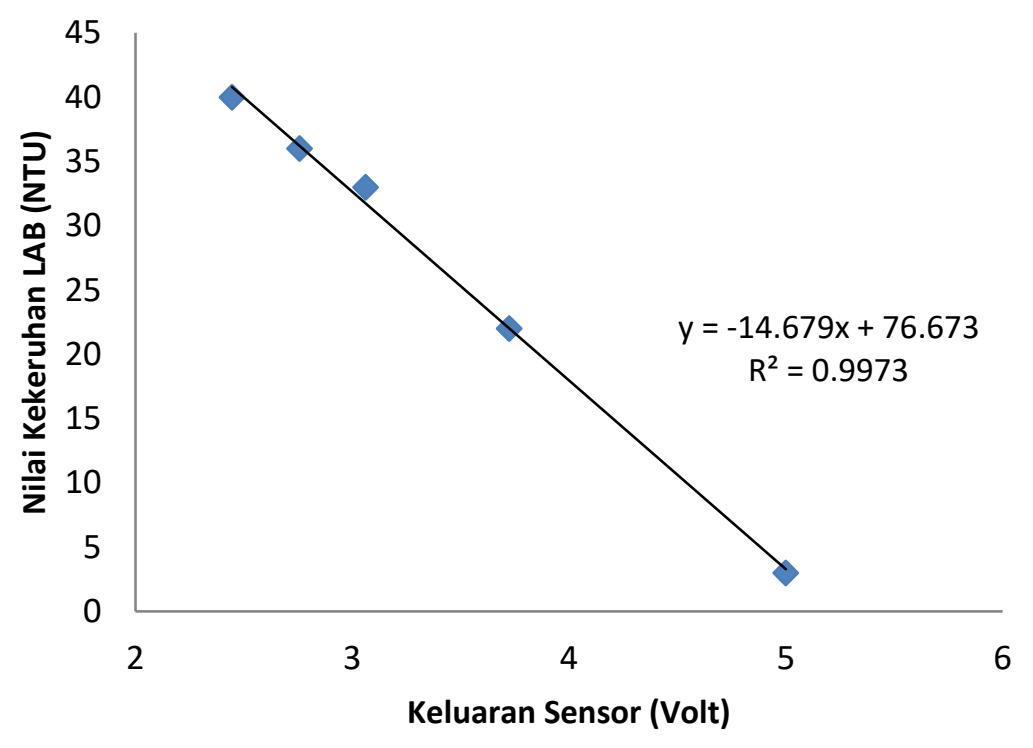

GAMBAR 4. Grafik hubungan tegangan keluaran sensor terhadap kekeruhan laboratorium

TABEL 3. Data nilai kekeruhan laboratorium dan kekeruhan sensor

\begin{tabular}{cccc}
\hline No Sampel & $\begin{array}{c}\text { Nilai Kekeruhan } \\
\text { LAB (NTU) }\end{array}$ & $\begin{array}{c}\text { Nilai Kekeruhan } \\
\text { Sensor (NTU) }\end{array}$ & $\begin{array}{c}\text { Kesalahan } \\
\text { Relatif }(\%)\end{array}$ \\
\hline 1 & 3 & 3,28 & 9,26 \\
2 & 22 & 22,01 & 0,038 \\
3 & 33 & 31,72 & 3,86 \\
4 & 36 & 36,2 & 0,56 \\
5 & 40 & 40,78 & 1,96 \\
\hline
\end{tabular}


Berdasarkan grafik diatas, terlihat nilai kekeruhan laboratorium berbanding terbalik dengan tegangan keluaran sensor dan memenuhi persamaan :

$$
y=-14.679 x-76.673
$$

Dengan y merupakan nilai kekeruhan yang dapat dibaca oleh sensor dalam satuan NTU dan $\mathrm{x}$ berupa perubahan tegangan keluaran sensor. Kemudian dari fungsi tersebut dapat diketahui besarnya kesalahan relatif pengukuran. Diperoleh nilai kesalahan relatif pengukuran maksimum ada pada sampel nomer 1 yaitu sebesar 9.26\%. Alat ini memiliki pengukuran yang terbatas yaitu untuk kekeruhan antara 3 - 40 NTU.

Grafik pada gambar 4 yaitu berbanding terbalik antara nilai kekeruhan laboratorium dengan tegangan keluaran sensor. Menandakan bahwa semakin keruh suatu larutan makan nilai tegangan keluaran sensor akan semakin kecil atau mendekati nol. Hal ini dikarenakan dari sifat photodioda yang bersifat sebagai resistor jika tidak dipancari cahaya. Dalam gelap, nilai tahanannya sangat besar sehingga tidak ada arus yang mengalir dan nilai tegangan sensor akan nol.

\section{c. Sensor Konduktivitas}

Pada karakterisasi sensor konduktivitas dilakukan dengan membandingkan hasil tegangan keluaran pada sensor dengan pengukuran sampel jumlah zat padat terlarut pada laboratorium. Hasil pengukuran dirangkum pada tabel 4 . Kesalahan relatif pengukuran dihitung menggunakan persamaan (1) sehingga diperoleh grafik pada gambar 5 .

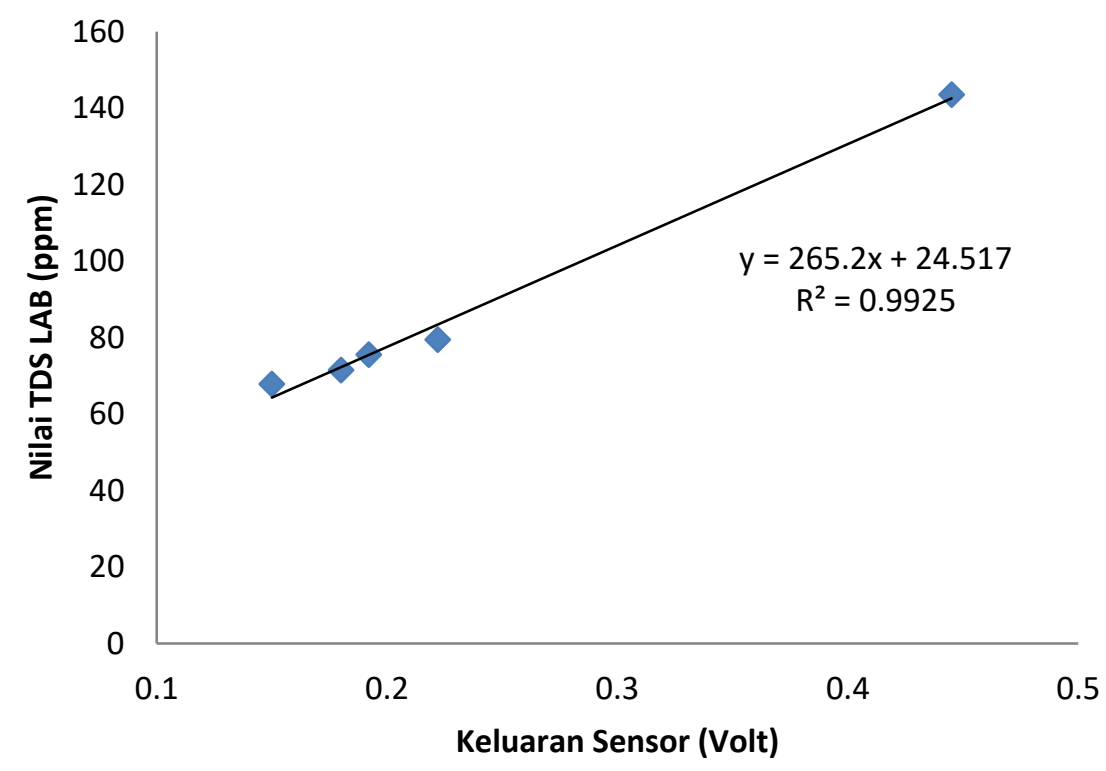

GAMBAR 5. Grafik hubungan tegangan keluaran sensor terhadap TDS laboratorium

TABEL 4. Data nilai TDS laboratorium dan TDS sensor

\begin{tabular}{cccc}
\hline No Sampel & $\begin{array}{c}\text { Nilai TDS } \\
\text { LAB (ppm) }\end{array}$ & $\begin{array}{c}\text { Nilai TDS } \\
\text { Sensor }(\mathbf{p p m})\end{array}$ & $\begin{array}{c}\text { Kesalahan Relatif } \\
(\boldsymbol{\%})\end{array}$ \\
\hline 2 & 67,85 & 64,29 & 5,23 \\
1 & 143,55 & 142,53 & 0,71 \\
3 & 71,5 & 72,25 & 1,05 \\
4 & 75,55 & 75,43 & 0,15 \\
5 & 79,45 & 83,39 & 4,96 \\
\hline
\end{tabular}


Berdasarkan grafik diatas, terlihat nilai TDS berbanding lurus dengan tegangan keluaran sensor dan memenuhi persamaan :

$$
y=265.2 x-24.517
$$

Dengan nilai y merupakan nilai TDS yang dapat dibaca oleh sensor dalam satuan ppm dan $\mathrm{x}$ berupa perubahan tegangan keluaran sensor. Kemudian dari fungsi tersebut dapat diketahui besarnya kesalahan relatif pengukuran. Diperoleh nilai kesalahan relatif pengukuran maksimum ada pada sampel nomer 2 yaitu sebesar $5.23 \%$. Alat ini memiliki pengukuran yang terbatas yaitu untuk sensor konduktivitas antara $64-142 \mathrm{ppm}$.

Grafik pada gambar 4 yaitu berbanding lurus antara nilai jumlah zat padat terlarut laboratorium dengan tegangan keluaran sensor. Menandakan bahwa semakin besar jumlah zat padat terlarut, maka nilai tegangan keluaran sensor akan semakin besar pula. Hal ini disebabkan banyaknya jumlah ionion didalam larutan berbanding lurus dengan besarnya nilai jumlah zat padat terlarut. Semakin banyak ion didalam larutan makan beda potensial yang dapat dihasilkan akan semakin besar juga, dimana menandakan semakin banyak juga jumlah padatan terlarutnya.

\section{d. Pengujian Sampel}

Pengujian sistem pengukuran kekeruhan dan jumlah zat padat terlarut air ini dilakukan pada bulan Juli 2017. Pengujian dilakukan dengan pembacaan sensor suhu ds18b20, photodioda, sensor konduktivitas. Digunakan sembilan sampel larutan uji yang berbeda pada pengujian ini dengan volume air $100 \mathrm{ml}$.

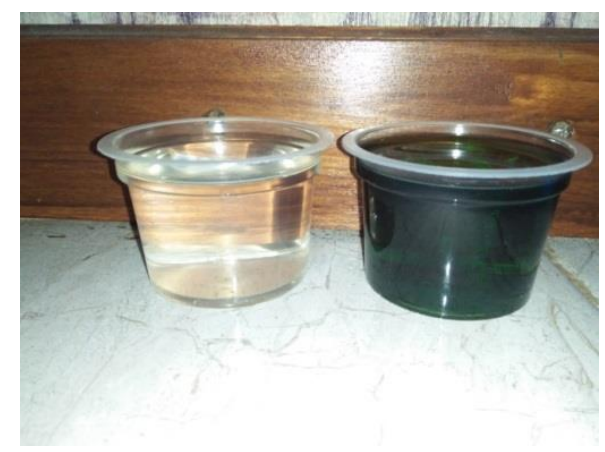

GAMBAR 6. Sampel larutan uji

TABEL 5. Daftar sampel larutan uji

\begin{tabular}{cccc}
\hline Bahan & $\begin{array}{c}\text { Nilai Suhu } \\
\text { Sensor }(\mathbf{C})\end{array}$ & $\begin{array}{c}\text { Nilai Kekeruhan } \\
\text { Sensor }(\mathbf{N T U})\end{array}$ & $\begin{array}{c}\text { Nilai TDS Sensor } \\
(\mathbf{p p m})\end{array}$ \\
\hline Air PAM & 26.06 & 3.27 & 142.53 \\
Air Sungai & 26.4 & 3.27 & 49.02 \\
Air Danau & 26.37 & 3.27 & 49.26 \\
Tanah 1/4sdk & 27.25 & 51.6 & 139.64 \\
Tanah 1/2sdk & 27,06 & 62.48 & 125.74 \\
Tanah 1sdk & 26.87 & 73.84 & 123.67 \\
Minyak 2sdk & 26.44 & 3.27 & 24.51 \\
Air Kalimalang & 26.62 & 3.27 & 87.37 \\
Pewarna Tekstil & 27.12 & 41.42 & 165.25 \\
1/8sdk & & & \\
\hline
\end{tabular}


Dari hasil pengujian kesembilan jenis larutan diatas, dapat diketahui bahwa pengujian ini dapat dilakukan untuk rentang pengujian yang sudah dilakukan pada tahap karakterisasi. Untuk air sungai diambil di daerah Citayam, air danau diambil di daerah Cikaret, sedangkan untuk air kali menggunakan air yang diambil dari daerah Kalimalang.

Untuk parameter kekeruhan, kurang sensitifnya sensor photodioda pada saat pendeteksian air yang bening sehingga nilai pembacaan untuk air PAM, air sungai, air danau, campuran minyak, dan air kali terbaca sama pada sensor photodioda. Sensor photodioda ini memiliki respon yang cukup sensitif dalam pembacaan nilai kekeruhan $\geq 20$ NTU dan alat ini memiliki rentang pengukuran untuk kekeruhan antara 3 - 40 NTU.

Pada daftar nilai pengujian sampel dengan parameter TDS, diperoleh nilai TDS paling tinggi ada pada larutan dengan pewarna tekstil $1 / 8$ sdk atau sampel no 9. Menurut $W H O$ nilai kemurnian air yang baik dibatasi dengan nilai $T D S$ maksimum $30 \mathrm{ppm}$ saja. Tingginya level TDS memperlihatkan hubungan negatif dengan beberapa parameter lingkungan air yang menyebabkan meningkatnya toksisitas pada organisme didalamnya, serta membuat rasa tidak enak pada lidah dan rasa mual.

\section{SIMPULAN}

Karakterisasi sensor yang telah dilakukan dengan menggunakan mikrokontroler arduino uno, maka dapat disimpulkan bahwa sensor photodioda dapat bekerja dalam rentang pengukuran $3-40$ NTU, dan sensor konduktivitas dapat bekerja dalam rentang $64-142$ ppm. Sedangkan untuk kesalahan relatif pengukuran maksimum yaitu, ds $18 \mathrm{~b} 20$ sebesar $3.53 \%$, sensor photodioda sebesar 9.26\%, dan sensor konduktivitas sebesar 5.23\%. Dengan begitu, maka masing-masing sensor tersebut dapat diaplikasikan pada sistem deteksi kekeruhan dan jumlah zat padat terlarut dalam air yang portable.

\section{REFERENSI}

[1] Deril, M., \& Noviriani. Uji Parameter Air Minum Dalam Kemasan (AMDK) di Kota Surabaya. Jurnal Ilmiah Teknik Lingkungan Vol.6 No.1.

[2] Nasrudin, A. A., \& Dzulkiflih. (2015). Rancang Bangun Aplikasi Lux meter BH1750 Sebagai Alat Ukur Kekeruhan Air Berbasis Mikrokontroler. Jurnal Inovasi Fisika Indonesia.

[3] Yudha, Y. A., Pakereng, M. I., \& Wellem, T. (2013). Perancangan Dan Implementasi Sistem Monitoring Suhu Ruangan Penyimpanan Vaksin Berbasis Mikrokontroler. Universitas Kristen Satya Wacana. 
Spektra: Jurnal Fisika dan Aplikasinya http://doi.org/10.21009/SPEKTRA
Volume 2 Nomor 2,

Agustus 2017
p-ISSN: 2541-3384

e-ISSN: 2541-3392 